\title{
Simulação CFD do escoamento em uma célula eletroquímica de teste de corrosão utilizando o software OpenFOAM.
}

\author{
Maioli, A. G. ${ }^{1}$; Maioli, C. G. ${ }^{1}$; Martins, M. F. ${ }^{1}$ \\ 1 Programa de Pós-Graduação em Engenharia Mecânica, Universidade Federal do Espírito Santo, Vitória, ES, Brasil
}

\begin{abstract}
Resumo
Com o avanço da tecnologia dos computadores e capacidade de processamento, os softwares de CFD estão ficando cada vez mais poderosos e versáteis. Os softwares mais desenvolvidos e utilizados são os comercias, como Ansys CFX e FLUENT, porém apresentam custos relativamente altos para a obtenção de licenças. $O$ trabalho apresenta um estudo do escoamento em uma célula eletroquímica de teste de corrosão contendo um eletrodo disco rotatório, utilizando o software gratuito OpenFOAM, para servir de alternativa aos softwares comerciais. O principal problema encontrado foi a difícil convergência da solução ao se refinar a malha em torno do rotor. Isso foi contornado simulando primeiro para uma malha mais grossa, depois em uma um pouco mais refinada com esquema de discretização de primeira ordem, e, por fim, alterando para um esquema de segunda ordem para melhorar a precisão, obtendo bons resultados condizentes com a teoria.
\end{abstract}

Keywords (Palavras chaves): Eletrodo disco rotatório, CFD, OpenFOAM.

\section{Introdução}

Muitos problemas encontrados na indústria estão relacionados com a corrosão associada à erosão. Um ensaio para analisar a influência do escoamento nesse problema é a célula eletroquímica contendo eletrodo disco rotatório.

Atualmente, um importante software que aparece como uma opção aos comerciais é o OpenFOAM. Ele é um software gratuito e de código aberto, que está em crescente uso para a simulação de escoamentos e outros problemas de engenharia.

O objetivo deste trabalho é utilizar o OpenFOAM para simular o eletrodo disco rotatório, avaliando sua capacidade e a validação teórica dos seus resultados.

\section{Caracterização e modelagem do problema}

Os eletrodos disco rotatório pertencem ao grupo dos eletrodos hidrodinâmicos, onde há o transporte de massa na sua superfície e, consequentemente, a magnitude da corrente durante as reações no eletrodo é controlada por convecção das espécies eletroativas, causada pela rotação do eletrodo ou por agitação da solução (OPEKAR \& BERAN, 1975).

O caso estudado neste trabalho será uma célula eletroquímica que contém um eletrodo disco rotatório, feito de aço 1020 com 9 mm de diâmetro, coberto por um revestimento isolante em perfil cilindro infinito com $20 \mathrm{~mm}$ de diâmetro e $35 \mathrm{~mm}$ de comprimento, esquematizado na Figura 1. Para a modelagem, foram consideradas como condições de contorno uma velocidade nula nas paredes e uma velocidade de $10,472 \mathrm{rad} / \mathrm{s}$ para o rotor. Para esse caso, temos um número de Reynolds $R e=1112,15$, o que caracteriza o escoamento como laminar.

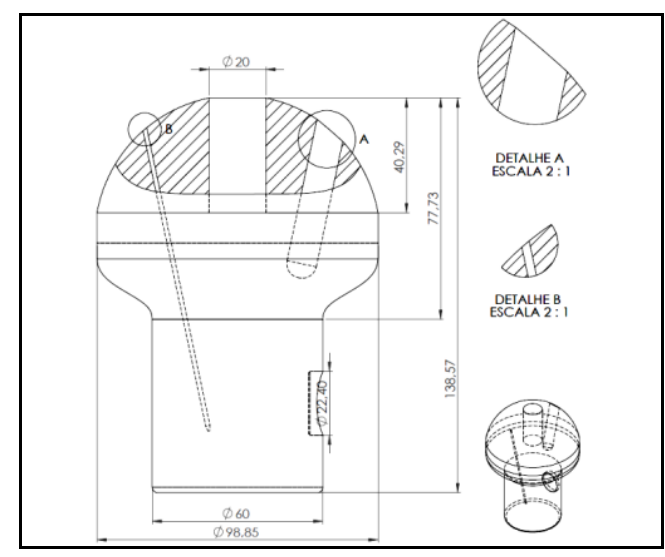

Figura 1: Domínio de cálculo da célula eletroquímica.

\section{Resultados e discussões}

A simulação foi realizada no software OpenFOAM, com o solver simpleFoam, e utilizando paralelização. Para tentar atingir um bom resultado, foram necessárias 
diversas simulações, modificando-se parâmetros como métodos de discretização e o refino da malha, devido a problemas de convergência. Para contornar o problema, optou-se por fazer uma simulação sequencial, simulando primeiro para uma malha mais grossa, depois em uma malha um pouco mais refinada com esquemas de discretização de primeira ordem e, por fim, alterando para um esquema de segunda ordem para melhorar a precisão.

A Figura 2 mostra uma comparação para os vetores de velocidade encontrados na simulação com os propostos na teoria por Opekar e Beran (1975). A simulação apresentou bons resultados em relação à teoria, sendo importante notar na vista lateral a influência dos eletrodos, fazendo com que o escoamento não chegue exatamente perpendicular à base inferior do rotor.

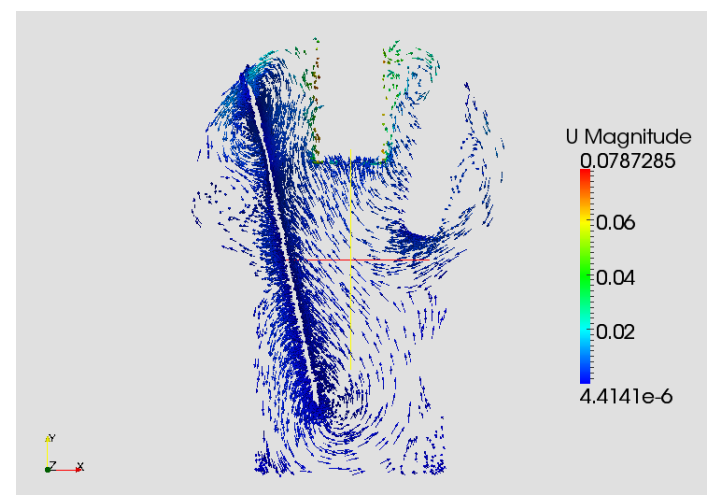

(a)

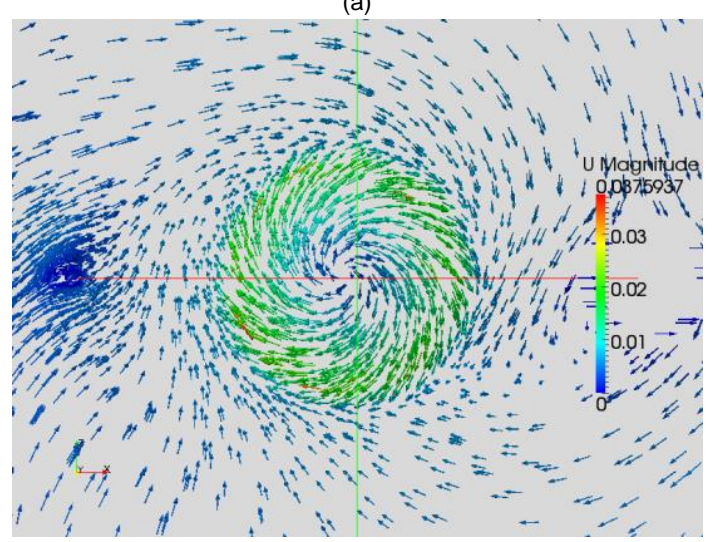

(b)
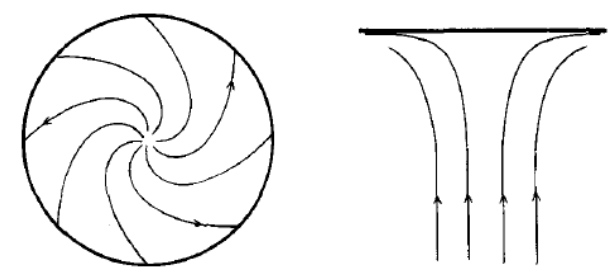

(c)

Figura 2: Comparação para os vetores de velocidade: (a) seção transversal; (b) corte abaixo do rotor; (c) teórico.

Opekar e Beran (1975) também propuseram valores teóricos para as velocidades radial e perpendicular dentro da camada limite na superfície inferior do rotor. A Figura 3 apresenta uma comparação entre os valores teóricos e os encontrados na simulação para essas velocidades, mostrando que os resultados obtidos seguem o padrão proposto na teoria.

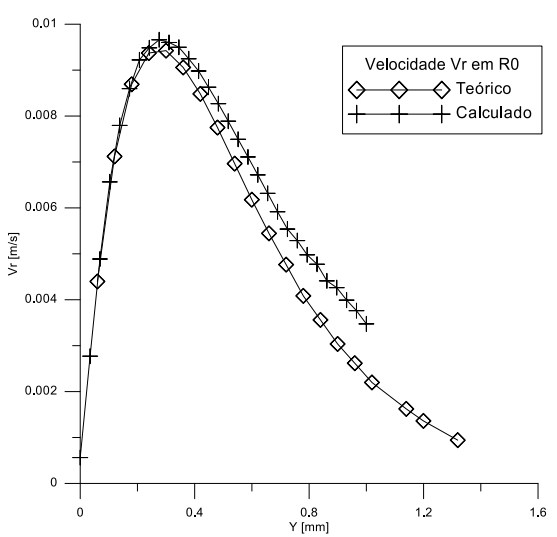

(a)

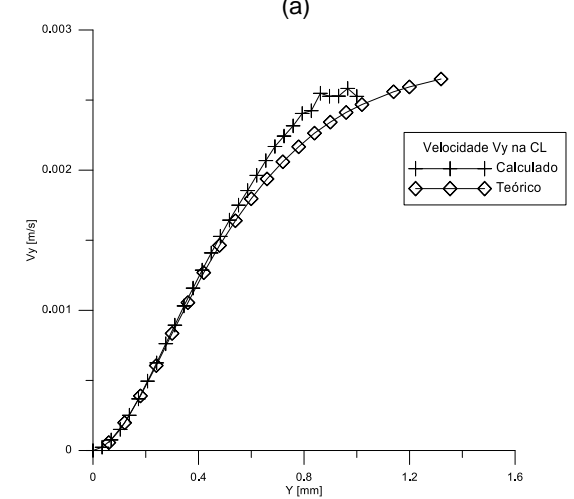

(b)

Figura 3: Velocidades na camada limite: (a) velocidade radial em $\mathrm{R} 0=5 \mathrm{~mm}$ do centro do rotor; (b) velocidade perpendicular.

\section{Comentários finais}

O caso estudado possui uma geometria complexa e malha não estruturada, e causou problemas relacionados à convergência da solução. Contudo, foram obtidos bons resultados, condizentes com a teoria para o escoamento num eletrodo disco rotatório.

O software OpenFOAM atendeu às expectativas. Apresentou uma excelente possibilidade de escolha e modificação dos parâmetros da simulação, como esquemas de discretização, e uma enorme capacidade de paralelização.

\section{Referências}

[1] OPEKAR, F.; BERAN, P. "Rotating Disk Electrodes". Netherlands: Journal of Electroanalytical Chemistry, 1975.

[2] MAIOLI, A. G.; MAIOLI, C. G. "Estudo inicial do software de simulação gratuito OpenFOAM". Projeto de Graduação (Engenharia Mecânica), Universidade Federal do Espírito Santo, Vitória, 2014. 